\title{
Evidence for Neural Effects of Repetition that Directly Correlate with Behavioral Priming
}

\section{Citation}

Maccotta, Luigi, and Randy Lee Buckner. 2004. Evidence for neural effects of repetition that directly correlate with behavioral priming. Journal of Cognitive Neuroscience 16(9): 1625-1632.

\section{Published Version}

doi:10.1162/0898929042568451

\section{Permanent link}

http://nrs.harvard.edu/urn-3:HUL.InstRepos:32116842

\section{Terms of Use}

This article was downloaded from Harvard University's DASH repository, and is made available under the terms and conditions applicable to Other Posted Material, as set forth at http:// nrs.harvard.edu/urn-3:HUL.InstRepos:dash.current.terms-of-use\#LAA

\section{Share Your Story}

The Harvard community has made this article openly available.

Please share how this access benefits you. Submit a story.

\section{Accessibility}




\title{
Evidence for Neural Effects of Repetition that Directly Correlate with Behavioral Priming
}

\author{
Luigi Maccotta and Randy L. Buckner
}

\begin{abstract}
Stimulus repetition associates with neural activity reductions during tasks that elicit behavioral priming. Here we present direct evidence for a quantitative relation between neural activity reductions and behavioral priming. Fifty-four subjects performed a word classification task while being scanned with functional MRI. Activity reductions were found in multiple high-level cortical regions including those within the prefrontal cortex. Importantly, activity within several of these regions, including the prefrontal cortex, cor-
\end{abstract}

\section{INTRODUCTION}

Repeated experience with a stimulus can lead to faster performance and more accurate identification-a behavioral phenomenon known as repetition priming (for reviews, see Roediger \& McDermott, 1993; Tulving \& Schacter, 1990; Schacter, 1987). Human imaging studies that elicit behavioral priming have consistently demonstrated neural effects of repetition, including, but not limited to, relative activity reductions in specific cortical regions (for reviews, see Henson, 2003; Schacter \& Buckner, 1998; Wiggs \& Martin, 1998). Parallel singleunit correlates in monkeys have also been identified (e.g., Rainer \& Miller, 2000).

Considerable progress has been made in characterizing these neural repetition effects. First, these effects appear to generalize across paradigms including visual and auditory stimuli as well as many task forms (Buckner, Koutstaal, Schacter, \& Rosen, 2000; Badgaiyan, Schacter, \& Alpert, 1999; Wagner, Desmond, Demb, Glover, \& Gabrieli, 1997; Demb et al., 1995; Raichle et al., 1994; for a recent review, see Henson, 2003). Second, repetitionrelated reductions occur in regions that are significantly active for novel items, suggesting that such effects target processing components normally engaged by the task. Third, not all cortical regions significantly active during task performance show an effect of repetition: Relative activity reductions tend to spare, for instance, early visual regions and regions involved in motor execution, while producing robust effects in high-level regions such as ones found in the late visual and frontal cortex (e.g.,

Washington University related with behavior such that greater activity reductions associated with faster performance. Whole-brain correlational analyses confirmed the observation of anatomic overlap between regions showing activity reductions and those showing direct brain-behavioral correlations. The finding of a quantitative relation between neural and behavioral effects in frontal regions suggests that repetition reduces frontally mediated processing in a manner that ultimately facilitates behavior.
Vuilleumier, Henson, Driver, \& Dolan, 2002; Koutstaal et al., 2001; Buckner, Goodman, et al., 1998). Repetition does not therefore have a general effect on all regions engaged by a task, but rather appears to influence a specific subset, potentially targeting specific processing components in the information processing hierarchy.

Despite these robust and reliable results, no direct correlation between activity reductions and behavioral priming have been reported (for an extensive review, see Henson, 2003) prompting some to question whether the phenomenon is epiphenomenal. Observed repetition effects may also reflect a phenomenon that is related to explicit recognition of repeated items (but see Dehaene, Naccache, Cohen, et al., 2001; Dehaene, Naccache, Le Clec'H, Koechlin, \& Mueller, 1998). The present event-related fMRI study used a large sample to test for a direct relation between neural repetition effects and behavioral priming. Fifty-four healthy young adults performed a word classification task on novel and repeated words while being imaged with fMRI. Neural repetition effects were directly regressed with behavioral facilitation effects across subjects. Results from regional and voxelwise analyses converged to indicate that a quantitative relation exists between neural activity reductions and behavioral priming in specific regions of the human cortex.

\section{RESULTS}

Behaviorally, repetition resulted in robust priming (Figure 1). Response time was significantly affected by repetition during a study phase immediately preceding 


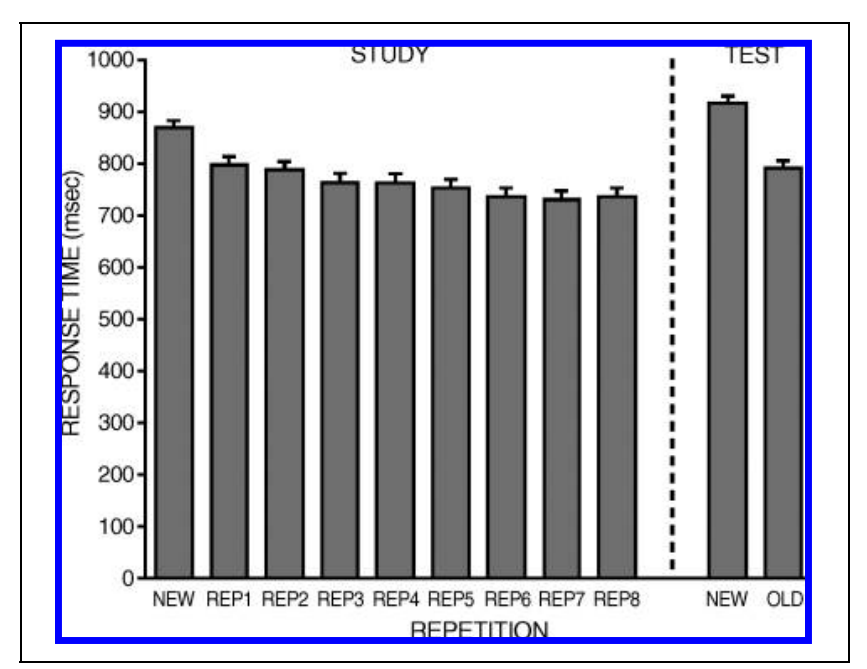

Figure 1. Mean behavioral response time as a function of item repetition in the study and test sessions of the experiment. Study session repeated items are indicated as "Rep1-Rep8." Repeated items during the test session were averaged across two functional runs and are indicated as "Old." Novel items are indicated as "New." Error bars represent standard error of the mean.

the functional imaging session [ANOVA, $F(8,53)=38.0$, $p<.001]$. During scanning, paired $t$ tests showed that old words were classified significantly faster $(791 \mathrm{msec})$ than new words [915 msec; $t(53)=22.81, p<.001]$, with no significant difference in accuracy $[95.5 \%$ and $94.4 \%$ for old and new words, respectively; $t(53)=1.81, n s]$.

The relation between behavioral priming and relative neural activity reductions was explored systematically beginning with an analysis using a priori regions, and followed by exploratory mapwise and post hoc regional analyses. In the first analysis, amplitude estimates derived from independently defined a priori regions were used to compute regional repetition effects. The size of the regional neural repetition effect was then directly regressed across subjects against the amount of behavioral priming. Use of a priori regions allowed unbiased estimation of repetition effects and their relation to behavioral facilitation in each prespecified cortical region. Choice of regions explored in the first analysis was motivated by previous studies (e.g., Buckner, Goodman, et al., 1998), and included an early visual region near the calcarine cortex and a region near the motor cortex (as controls), a late visual region near the posterior fusiform gyrus, and a prefrontal region near the inferior frontal gyrus (Figure 2A-D). All regions were in the left hemisphere.
Replicating previous event-related studies, repetition resulted in significant reduction of neural activity in high-level cortical regions, whereas early visual and motor regions did not show significant repetition effects (Figure 2E-H). The region near calcarine cortex did not show a significant effect of repetition, with similar activity levels for novel and repeated items [Figure 2E; paired $t$ test, $t(53)=1.04, n s]$. Conversely, the region centered near the posterior fusiform gyrus demonstrated significantly decreased activity for repeated items as compared to novel items [Figure 2F; $t(53)=5.47, p<.001$ ] Repetition effects were also observed in the region near the inferior frontal gyrus, with robust activity reductions for repeated words [Figure 2G; $t(53)=7.83, p<.001$ ] The region near motor cortex instead did not show significant group-level facilitation [Figure $2 \mathrm{H} ; t(53)=$ $0.62, n s]$. Thus, group-level repetition effects generally replicated previous findings (e.g., Buckner, Goodman, et al., 1998), showing specificity for high-level temporal and frontal regions, while sparing regions involved in early visual processing and response execution.

The relation between regional neural activity levels and behavioral response time was explored next. Regional neural repetition effects (computed as the difference between hemodynamic response amplitude for novel and repeated items) were regressed against behavioral repetition effects (computed as the difference between response times to novel and repeated items). Results of this analysis are shown in the right panels of Figure 2 (I-L). The visual regions showed minimal effects (Figure 2I; $r=.17, n s$; and Figure 2J; $r=.17, n s)$. Significant correlations were observed in the region centered near the inferior frontal gyrus (Figure $2 \mathrm{~K} ; r=.31, p<.05$ ), which had demonstrated robust group-level activity reductions for repeated items in the previous analysis. No correlation was observed in the region near motor cortex (Figure 2L; $r=.17, n s)$. Results of the regression analysis thus revealed a significant correlation between neural repetition effects and behavioral priming in the a priori region of prefrontal cortex, suggesting that behavioral facilitation is directly linked to activity reductions in frontal cortex. Analyses based on relative behavioral difference, as opposed to absolute differences, yielded highly similar results.

To further explore the relation between neural reductions and behavior, mapwise analyses were conducted that directly compared regions of activity reduction to

Figure 2. Correlation of neural and behavioral repetition effects in a priori regions. The left panels (A-D) display regions of interest in yellow on axial anatomical images. Regions near calcarine cortex (A), posterior fusiform gyrus (B), inferior frontal gyrus (C), and primary motor cortex (D) examined in this analysis were obtained from Logan et al. (2002), Maccotta et al. (2001), and data from an unpublished object localizer task. Group hemodynamic response time-courses for such regions are shown in the middle panels (E-H) for novel (red) and repeated (black) items. Percent amplitude reduction for repeated items is indicated for each region. Correlation plots regressing neural and behavioral repetition effects across the 54 subjects in each a priori region are displayed in the right panels (I-L). Late visual and prefrontal regions demonstrated significant repetition reductions, replicating previous results and indicating specificity of repetition effects. A quantitative relationship between neural repetition effects and behavior was revealed in the prefrontal region $(\mathrm{K})$. 


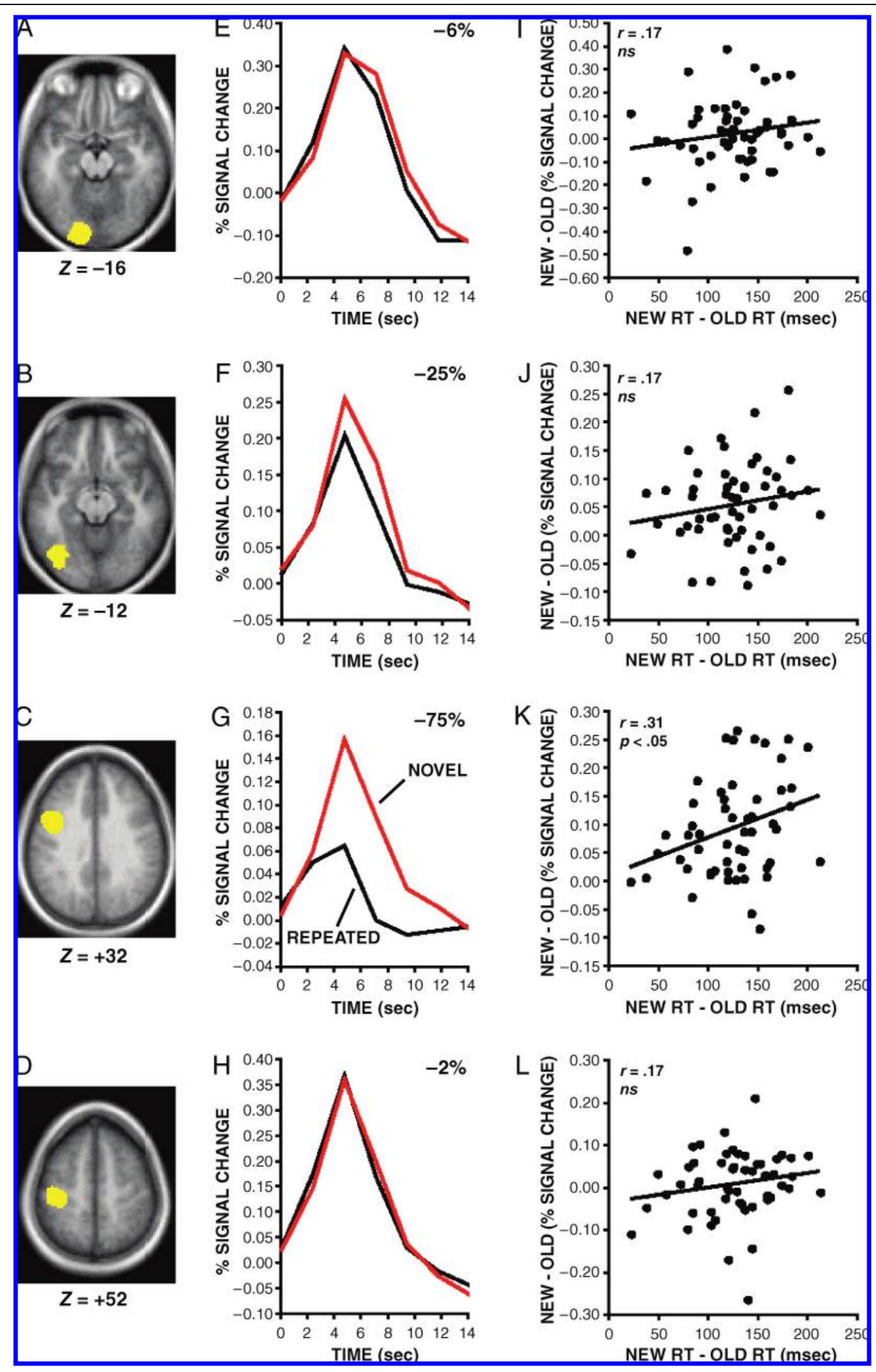




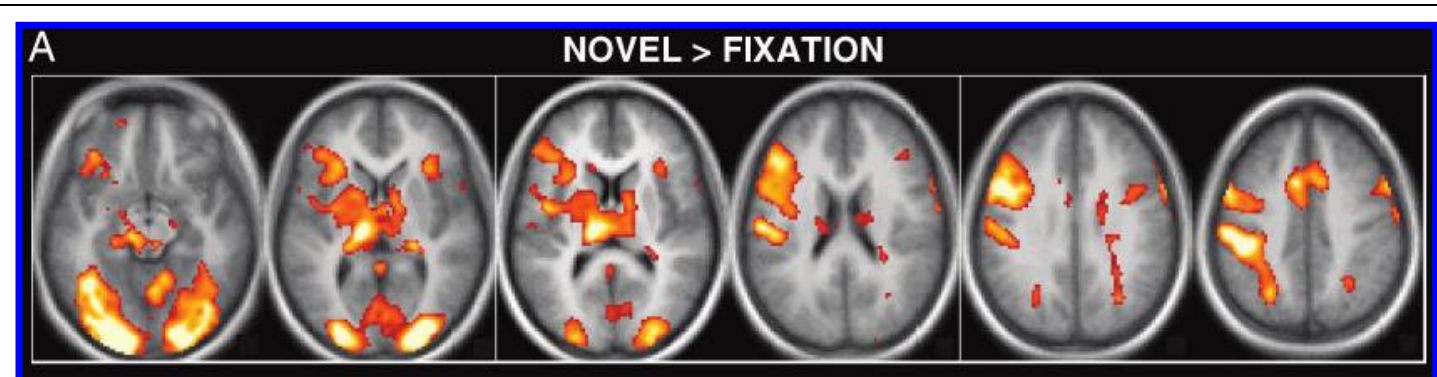

B

REPEATED > FIXATION

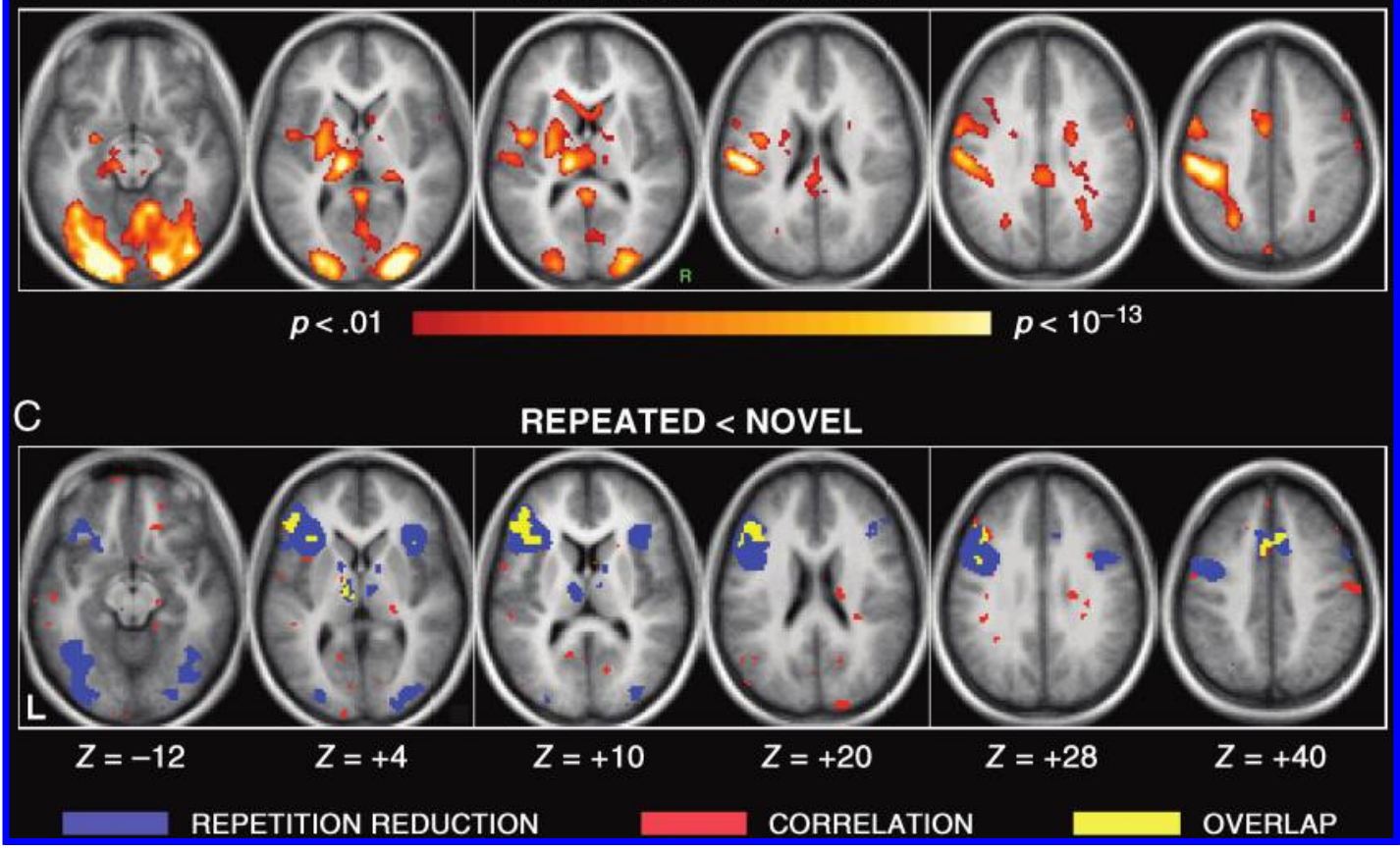

Figure 3. Frontal regions show a quantitative link between repetition reductions and behavioral priming. (A) Statistical activation maps comparing novel items to a baseline fixation condition revealed widespread activity in several regions of the occipital, temporal, frontal, and motor cortex. (B) Activation maps comparing repeated items to fixation revealed activation of a similar network, but with specific, robust reductions in the frontal regions and, to a lesser extent, in the temporal regions. (C) Whole-brain maps show the overlap between a significant neural repetition effect and a correlation with behavior. Voxels that showed both significant repetition-related activity reductions $(p<.01)$ and a significant correlation between neural and behavioral repetition effects $(p<.01)$ are depicted in yellow (blue colors and red colors represent significance only for the repetition and correlation effects, respectively). Note the overlap of repetition reduction and correlation in the prefrontal, SMA, and thalamic regions.

those showing brain-behavior correlation. Statistical activation maps were computed first by comparing amplitude levels for novel and repeated words to a baseline fixation condition, providing an estimate of those regions showing activity during the task, as has been explored in previous studies (Figure 3A and B). Processing of novel items led to activation of several cortical regions, including regions in occipital, temporal, frontal, and motor cortex (Figure 3A). When items were repeated, qualitative inspection revealed activation of similar regions of the cortex, albeit with reduced activity in specific regions, including portions of the frontal and temporal cortex (Figure 3B).

Maps were then constructed showing the voxelwise magnitude of the correlation between behavioral and neural facilitation effects. Results are shown in Figure 3C, which superimposes voxels demonstrating significant repetition-related activity reductions and significant correlation between neural and behavioral priming. Specific regions of the cortex that showed repetition-related activity reductions also showed a significant correlation between neural and behavioral priming, including regions of prefrontal cortex near BA 44 and pre-SMA, consistent with results of the previous analyses. Not all regions showing repetition-related activity reductions also showed a correlation between neural and behavioral priming. However, it is possible that threshold effects contribute to the appearance of specificity, concealing a weaker correlation in these regions. Consistent with this possibility, those regions showing the greatest activity 
reductions showed the most robust brain-behavior correlations.

Motivated by the prominent effects in frontal cortex along the inferior frontal gyrus, prefrontal subregions were explored that have functionally dissociated in past studies. Specifically, three separate regions were interrogated post hoc based on Gold and Buckner (2002), including regions near (1) BA 44, (2) BA 6, and (3) BA $45 / 47$. These three regions are reported as exploratory correlations as they were not intended for analysis prior to data collection. Regression plots appear in Figure 4. Of the three regions, BA 44 showed the strongest correlation (Figure 4A; $r=.40, p<.005$ ), whereas BA 45/47 and BA 6 showed weaker effects (Figure 4B-C; BA 6: $r=.21, n s ; \mathrm{BA} 45 / 47: r=.25, p=.07)$.

Taken together, the results of these analyses suggest a direct relation between neural activity reductions and behavioral priming in specific regions of the cortex, such as portions of frontal cortex (e.g., BA 44) and pre-SMA, which have been implicated in controlled processing.

\section{DISCUSSION}

The frequent observation of repetition resulting in reduced neural activity concurrent with behavioral facilitation suggests a link between neural repetition effects and behavioral priming (Henson, 2003; Schacter \& Buckner, 1998; Wiggs \& Martin, 1998). In the present study, the commonly observed pattern of activity reductions following item repetition was replicated, with the most prominent reductions observed in late visual cortex extending into inferior temporal cortex and frontal cortex. Moreover, a significant correlation between activity reductions and behavioral priming was observed in prefrontal cortex. Exploratory mapwise correlations further suggested that regions showing correlation overlapped with those demonstrating repetition-related reductions, involving the prefrontal regions and supplementary motor area. These results provide direct evidence that neural activity reductions associate with repetition priming. For these reasons, repetition-related activity reductions might be appropriately termed "neural priming," reflecting their direct link to certain behavioral priming effects that have long been studied in the behavioral literature (for reviews, see Roediger \& McDermott, 1993; Tulving \& Schacter, 1990; Schacter, 1987). Moreover, the quantitative relationship between behavioral and neural priming observed here across subjects is consistent with previous reports linking withinsubject levels of behavioral priming to corresponding changes in levels of neural priming across conditions (Simons, Koutstaal, Prince, Wagner, \& Schacter, 2003; van Turennout, Bielamowicz, \& Martin, 2003; Koutstaal et al., 2001; Henson, Shallice, \& Dolan, 2000; van Turennout, Ellmore, \& Martin, 2000; Wagner, Koutstaal, Maril, Schacter, \& Buckner, 2000).

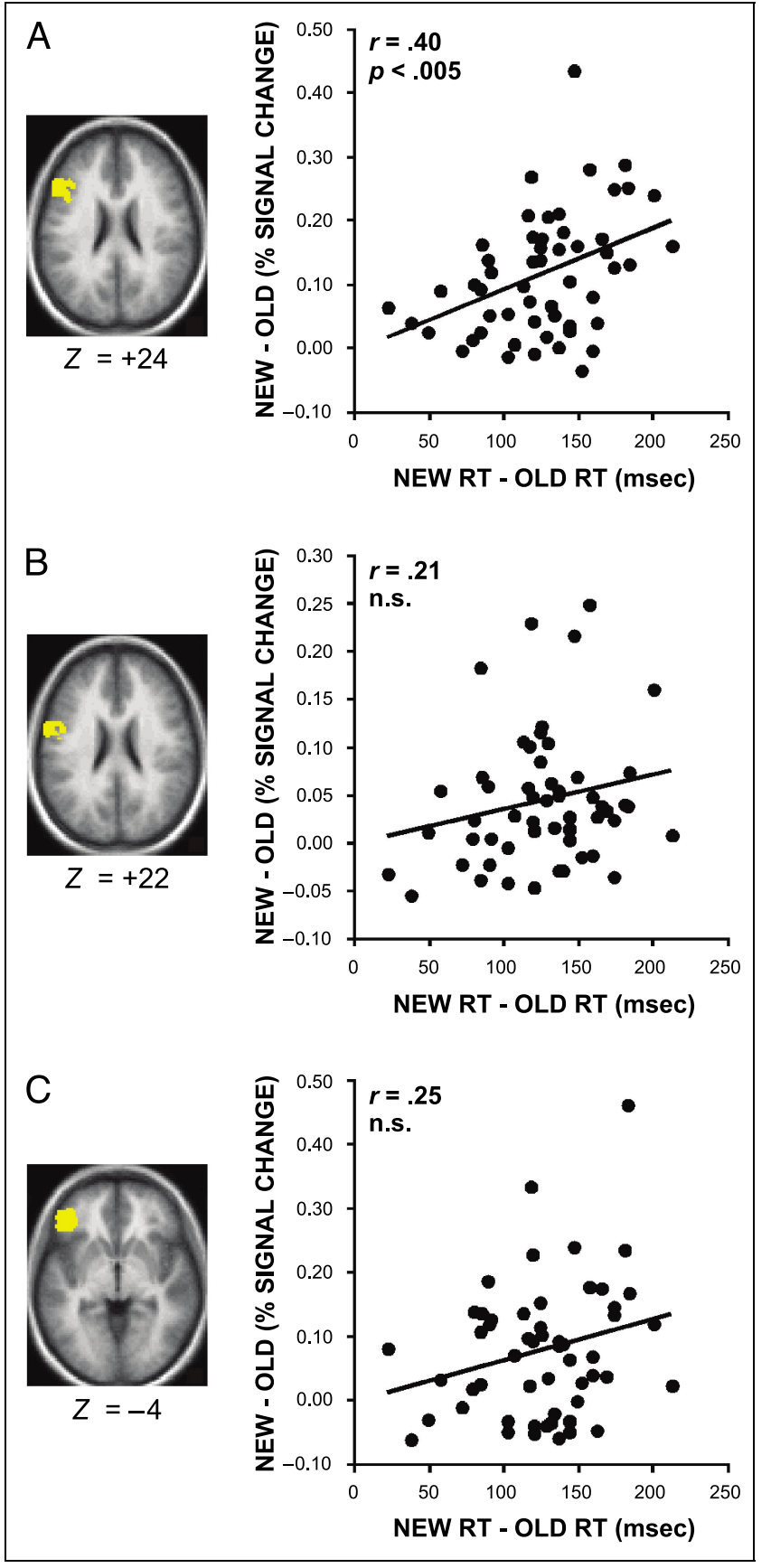

Figure 4. Correlation of neural and behavioral repetition effects in post hoc frontal regions. (A, B, C) The region at or near BA 44 (A) showed the strongest correlation between neural and behavioral priming $(p<.005)$, whereas the two other frontal regions showed at best a trend for a correlation (BA 6: $n s ; \mathrm{BA} 45 / 47: p=.07$ ). Regions are derived from Gold and Buckner (2002).

The correlation observed in frontal regions, in particular, along the inferior frontal gyrus including a region at or near BA 44 and to a lesser extent a region near BA 45/ 47 , suggests that a significant influence of repetition on behavior was through facilitation of frontally mediated processes. The finding of nonsignificant correlations in the other regions does not preclude their contribution 
in the processing facilitation evident at the behavioral level, as such apparent specificity may be due to a threshold effect, or a suboptimal definition of the region of interest. Nonetheless, anterior regions along the inferior frontal gyrus have consistently been implicated in controlled processing (Gold \& Buckner, 2002; Mesulam, 2002; Duncan, 2001; Wagner, Pare-Blagoev, Clark, \& Poldrack, 2001; Fletcher, Shallice, \& Dolan, 2000; Thompson-Schill, D’Esposito, Aguirre, \& Farah, 1997; Raichle et al., 1994) and also showed robust effects in the present study. Lesions to the frontal cortex can impair controlled task performance (Janowsky, Shimamura, Kritchevsky, \& Squire, 1989; Shallice, 1988; Norman \& Shallice, 1986; Stuss \& Benson, 1984; Petrides \& Milner, 1982; Milner, 1963, 1964). Repetition may affect these prefrontal regions by reducing their contribution to task performance as direct stimulus-response mappings form (Buckner, Koutstaal, et al., 2000; Raichle et al., 1994).

\section{METHODS}

\section{Subjects}

Fifty-four volunteers (28 women, mean age: 22.0, range: 18-37) were recruited from the Washington University community in return for payment or course credit. All were right-handed, native English speakers, had normal or corrected-to-normal vision, and reported no history of significant neurological problems. Subjects provided informed consent in accordance with the guidelines set by the Washington University Human Studies Committee.

\section{Task and Stimuli}

During an initial study phase, which took place during the initial structural imaging, subjects were presented with 30 English words (repeated over five nonconsecutive repetitions) and made living/nonliving decisions (cf. Kapur et al., 1994), indicating their choice with a right index/middle finger keypress. Two scanned test functional runs followed. Each functional run consisted of 124 image acquisitions, in which 50 old words (25 words repeated twice per run) and 50 new words were pseudorandomly intermixed with 50 trials of fixation baseline. The test task was identical to the study task. Stimuli were presented for $1600 \mathrm{msec}$ (288 msec ISI of fixation). By using an interstimulus interval (1888 $\mathrm{msec}$ total) that was different from the image acquisition time (2360 $\mathrm{msec}$ ), the hemodynamic response was sampled with a greater temporal resolution than would be achieved by a fixed locking between trial presentation and image acquisition (Maccotta, Zacks, \& Buckner, 2001; Miezin, Maccotta, Ollinger, Petersen, \& Buckner, 2000; Josephs, Turner, \& Friston, 1997). Specifically, oversampling occurred such that five trials were presented every four image acquisitions. Stimuli were abstract and concrete words (Demb et al., 1995) that appeared in Geneva 24-size font with each letter subtending approximately $1.2^{\circ}$ horizontal. Lists were equated for length (mean $=$ 6.56) and frequency (mean $=29.54$ ), with equal numbers of living and nonliving words.

\section{Image Acquisition Procedures}

Scans were conducted on a 1.5-T Vision scanner (Siemens, Erlangen, Germany) with a standard circularly polarized head coil. Foam cushions and a thermoplastic face mask were used to minimize head movement. Headphones decreased scanner noise and allowed verbal communication. Subjects made responses with a hand-held fiber-optic keypress connected to a Psyscope button box and a Power Macintosh computer (Apple, Cupertino, CA). Stimuli were projected (AmPro LCD150) onto a screen at the head of the bore. Subjects viewed the screen via a mirror attached to the head coil.

Structural images were acquired using a T1-weighted high-resolution sagittal MP-RAGE sequence $(\mathrm{TR}=$ $9.7 \mathrm{msec}, \mathrm{TE}=4 \mathrm{msec}$, flip angle $=10^{\circ}$, TI $=20 \mathrm{msec}$, $\mathrm{TD}=200 \mathrm{msec}, 1.25 \times 1 \times 1 \mathrm{~mm})$. Functional images followed using an asymmetric spin-echo echo-planar sequence sensitive to blood oxygenation level-dependent (BOLD) contrast (whole-brain TR $=2.36 \mathrm{sec}$, $\mathrm{TE}=$ $37 \mathrm{msec}$, flip angle $=90^{\circ}, 3.75 \times 3.75 \mathrm{~mm}$ in-plane resolution). Whole-brain coverage was achieved by acquiring sets of 16 contiguous, 8-mm-thick axial images parallel to the anterior-posterior commissural plane, with one set acquired every $2.36 \mathrm{sec}$. Hereafter, we refer to each 16-slice image set as an "image acquisition" and its position in time as a "timepoint." The first four image acquisitions in each functional run were discarded to allow stabilization of longitudinal magnetization.

\section{MR Data Preprocessing}

Functional data were first corrected for odd/even slice intensity differences, and for motion using a rigid-body rotation and translation algorithm (Snyder, 1996). Differences in timing between slices due to acquisition order were adjusted with sinc interpolation. Voxelwise linear slope was removed, and whole-brain intensity was normalized to 1000 for each functional run. Structural and functional volumes were then transformed into stereotaxic atlas space (Tailarach \& Tournoux, 1988) using procedures described previously (Maccotta et al., 2001). Transformed images used 2-mm isotropic voxels.

\section{Regional Analyses}

Regional analyses explored signal magnitude estimates within a set of a priori regions that spanned early visual cortex, late visual cortex, prefrontal cortex, and the 
motor cortex. Regional analyses afford considerable power by reducing the number of multiple comparisons and averaging multiple voxels within each region, thereby increasing signal-to-noise. Moreover, because regions were derived a priori, their signal estimates represent unbiased estimates of the effects. Regions were derived from three sources. First, regions involved in early and late stages of visual processing were defined using data from an object localizer experiment performed in a separate experiment in an independent group of subjects ( $n=30$ subjects; similar to Malach et al., 1995). Regions were defined based on specific blocked-task comparisons contrasting intact with scrambled object stimuli, and both intact and scrambled stimuli with a low-level reference fixation condition. Voxelwise activation maps were calculated for each comparison of interest with an implementation of the general linear model (analyses identical to Gold \& Buckner, 2002; Logan, Sanders, Snyder, Morris, \& Buckner, 2002). Three-dimensional regions of interest were defined to include all suprathreshold voxels $(p<.001)$ within $12 \mathrm{~mm}$ of an activation peak. Regions near the calcarine cortex (peak location near $-17,-93,-17$, based on Tailarach \& Tournoux, 1988) and the posterior fusiform gyrus (peak: $-36,-73,-13$ ) were defined in this fashion. Second, regions in the frontal cortex associated with controlled processing of verbal stimuli were taken directly from Logan et al. (2002) (based on data from Konishi, Donaldson, \& Buckner, 2001, $n=39$ subjects; and Gold \& Buckner, 2002, $n=24$ subjects). These regions used the same statistical criteria, but were defined based on a contrast comparing semantic and letter tasks involving verbal stimuli to a reference fixation. Regions near the inferior frontal gyrus (peak: -43 , 3,32 ), BA 44 (peak: $-47,17,24$ ), BA 6 (peak: $-55,-1$, 28), and BA 45/47 (peak: $-45,35,-4$ ) were constructed using this dataset. Finally, a region near the motor cortex involved in response execution was taken directly from Maccotta et al. (2001) ( $n=17$ subjects), again with the same statistical criteria applied to a contrast comparing right and left index finger responses during a mental rotation task (peak: $-37,-25,50$ ).

Regional estimation of hemodynamic response amplitude was achieved using an implementation of the general linear model (Miezin et al., 2000). Amplitude estimates for each subject, for each condition, were derived by computing the difference between the average signal magnitude at the third and fourth timepoint (roughly corresponding to the peak of the hemodynamic response in most regions) and the average signal magnitude at the first and eighth timepoint (corresponding to the baseline of the hemodynamic response) (Wheeler, Petersen, \& Buckner, 2000). Regional amplitude estimates were entered into statistical analyses (repeated-measures ANOVA and paired $t$ test) using a mixed-effects model treating subjects as a betweensubject effect.

\section{Whole-Brain Analyses}

Exploratory whole-brain statistical maps for event-related experiments were also generated to confirm and extend the results obtained from a priori regional analyses. For each comparison of interest, a mixed effect statistical model $t$ test was computed at each voxel. Estimates for each condition were based on a delayed boxcar convolved with a gamma function (Boynton, Engel, Glover, \& Heeger, 1996), excluding linear trend and constant effects, and averaged across all voxels within a given region. Resulting $t$ statistics were converted to $z$ statistics by mapping $p$ values obtained to equivalent $p$ values on a normal distribution. Whole-brain activation maps were then constructed by plotting the $z$-score of each voxel.

\section{Acknowledgments}

We thank Jeremy Gray and Todd Braver for assistance with data collection, Kate O'Brien for help with behavioral data analysis, and Abraham Snyder and Mark McAvoy for support with MRI data analysis. We also thank Rik Henson and Cindy Lustig for helpful discussions, and three anonymous reviewers for comment. This work was supported by NIH grant MH57506, the Howard Hughes Medical Institute, and the James S. McDonnell Foundation

Reprint requests should be sent to Luigi Maccotta, Department of Psychology, Washington University, Campus Box 1125, One Brookings Drive, St. Louis, MO 63130, or via e-mail: maccottl@ medicine.wustl.edu.

The data reported in this experiment have been deposited in the fMRI Data Center (http://www.fmridc.org). The accession number is 2-2004-116AR.

\section{REFERENCES}

Badgaiyan, R. D., Schacter, D. L., \& Alpert, N. M. (1999). Auditory priming within and across modalities: Evidence from positron emission tomography. Journal of Cognitive Neuroscience, 11, 337-348.

Boynton, G. M., Engel, S. A., Glover, G. H., \& Heeger, D. J. (1996). Linear systems analysis of functional magnetic resonance imaging in human V1. Journal of Neuroscience, 16, 4207-4221.

Buckner, R. L., Goodman, J., Burock, M., Rotte, M., Koutstaal, W., Schacter, D. L., Rosen, B. R., \& Dale, A. M. (1998). Functional-anatomic correlates of object priming in humans revealed by rapid presentation event-related f MRI. Neuron, 20, 285-296.

Buckner, R. L., Koutstaal, W., Schacter, D. L., \& Rosen, B. R. (2000). Functional MRI evidence for a role of frontal and inferior temporal cortex in amodal components of priming. Brain, 123, 620-640.

Dehaene, S., Naccache, L., Cohen, L., Le Bihan, D., Mangin, J.-F., Poline, J.-B., \& Riviere, D. (2001). Cerebral mechanisms of word masking and unconscious repetition priming. Nature Neuroscience, 4, 752-758.

Dehaene, S., Naccache, L., Le Clec'H, G., Koechlin, E., \& Mueller, M. (1998). Imaging unconscious semantic priming. Nature, 395, 597-600.

Demb, J. B., Desmond, J. E., Wagner, A. D., Vaidya, C. J., Glover, G. H., \& Gabrieli, J. D. (1995). Semantic encoding and retrieval in the left inferior prefrontal cortex: A 
functional MRI study of task difficulty and process specificity. Journal of Neuroscience, 15, 5870-5878.

Duncan, J. (2001). An adaptive coding model of neural function in prefrontal cortex. Nature Reviews: Neuroscience, 2, 820-829.

Fletcher, P. C., Shallice, T., \& Dolan, R. J. (2000). "Sculpting the response space"-An account of left prefrontal activation at encoding. Neuroimage, 12, 404-417.

Gold, B. T., \& Buckner, R. L. (2002). Common prefrontal regions coactivate with dissociable posterior regions during controlled semantic and phonological tasks. Neuron, 35, 803-812.

Henson, R. N. A. (2003). Neuroimaging studies of priming. Progress in Neurobiologv, 70, 53-81.

Henson, R. N. A., Shallice, T., \& Dolan, R. (2000). Neuroimaging evidence for dissociable forms of repetition priming. Science, 287, 1269-1272.

Janowsky, J. S., Shimamura, A. P., Kritchevsky, M., \& Squire, L. R. (1989). Cognitive impairment following frontal lobe damage and its relevance to human amnesia. Behavioral Neuroscience, 103, 548-560.

Josephs, O., Turner, R., \& Friston, K. (1997). Event-related f MRI. Human Brain Mapping, 5, 243-248.

Kapur, S., Craik, F. I., Tulving, E., Wilson, A. A., Houle, S., \& Brown, G. M. (1994). Neuroanatomical correlates of encoding in episodic memory: Levels of processing effect. Proceedings of the National Academv of Sciences. U.S.A., 91, 2008-2011.

Konishi, S., Donaldson, D. I., \& Buckner, R. L. (2001). Transient activation during block transition. Neuroimage, 13, 364-374.

Koutstaal, W., Wagner, A. D., Rotte, M., Maril, A., Buckner, R. L., \& Schacter, D. L. (2001). Perceptual specificity in visual object priming: Functional magnetic resonance imaging evidence for laterality difference in fusiform cortex. Neuropsychologia, 39, 184-199.

Logan, J. M., Sanders, A. L., Snyder, A. Z., Morris, J. C., \& Buckner, R. L. (2002). Under-recruitment and nonselective recruitment: Dissociable neural mechanisms associated with aging. Neuron, 33, 827-840.

Maccotta, L., Zacks, J. M., \& Buckner, R. L. (2001). Rapid self-paced event-related functional MRI: feasibility and implications of stimulus- versus response-locked timing. Neuroimage, 14, 1105-1121.

Malach, R., Reppas, J. B., Benson, R. R., Kwong, K. K., Jiang, H., Kennedy, W. A., Ledden, P. J., Brady, T. J., Rosen, B. R., \& Tootell, R. B. H. (1995). Object-related activity revealed by functional magnetic resonance imaging in human occipital cortex. Proceedings of the National Academv of Sciences. U.S.A., 92, 8135-8139.

Mesulam, M.-M. (2002). The human frontal lobes: Transcending the default mode through contingent coding. In D. T. Stuss \& R. T. Knight (Eds.), Principles of frontal lobe function (pp. 8-31). New York: Oxford University Press.

Miezin, F. M., Maccotta, L., Ollinger, J. M., Petersen, S. E., \& Buckner, R. L. (2000). Characterizing the hemodynamic response: Effects of presentation rate, sampling procedure, and the possibility of ordering brain activity based on relative timing. Neuroimage, 11, 735-759.

Milner, B. (1963). Effects of different brain lesions on card sorting. Archives of Neurology, 9, 90-100.

Milner, B. (1964). Some effects of frontal lobectomy in man. In J. M. Warren \& K. Akert (Eds.), The frontal granular cortex and behavior (pp. 313-334). New York: McGraw-Hill.

Norman, D. A., \& Shallice, T. (1986). Attention to action: Willed and automatic control of behavior. In R. J. Davidson, G. E. Schwartz, \& D. Shapiro (Eds.), Consciousness and self-regulation (pp. 1-18). New York: Plenum.

Petrides, M., \& Milner, B. (1982). Deficits on subject-ordered tasks after frontal- and temporal-lobe lesions in man. Neuropsychologia, 20, 249-262.

Raichle, M. E., Fiez, J. A., Videen, T. O., MacLeod, A. M., Pardo, J. V., Fox, P. T., \& Petersen, S. E. (1994). Practice-related changes in human brain functional anatomy during nonmotor learning. Cerebral Cortex, 4, 8-26.

Rainer, G., \& Miller, E. K. (2000). Effects of visual experience in the representation of objects in the prefrontal cortex. Neuron, 27, 179-189.

Roediger, H. L., III, \& McDermott, K. B. (1993). Implicit memory in normal human subjects. In F. Boller \& J. Grafman (Eds.), Handbook of neuropsychology (vol. 8, pp. 63-131). Amsterdam: Elsevier.

Schacter, D. L. (1987). Implicit memory: History and current status. Lournal of Experimental Psychology. Learning. Memory and Cognition, 13, 501-518.

Schacter, D. L., \& Buckner, R. L. (1998). Priming and the brain. Neuron, 20, 185-195.

Shallice, T. (1988). From neuropsychology to mental structure. Cambridge: Cambridge University Press.

Simons, J. S., Koutstaal, W., Prince, S., Wagner, A. D., \& Schacter, D. L. (2003). Neural mechanisms of visual object priming: Evidence for perceptual and semantic distinctions in fusiform cortex. Neuroimage, 19, 613-626.

Snyder, A. Z. (1996). Difference image versus ratio image error function forms in PET-PET realignment. In R. Myer, V. J. Cunnigham, D. L. Bailey \& T. Jones (Eds.), Quantification of brain function using PET (pp. 131-137). San Diego: Academic Press.

Stuss, D. T., \& Benson, D. F. (1984). Neuropsychological studies of the frontal lobes. Psvchological Bulletin. 95, 3-28

Tailarach, J., \& Tournoux, P. (1988). Co-planar stereotaxic atlas of the buman brain. New York: Thieme.

Thompson-Schill, S. L., D'Esposito, M., Aguirre, G. K., \& Farah, M. J. (1997). Role of left inferior prefrontal cortex in retrieval of semantic knowledge: A reevaluation. Proceedings of the National Academv of Sciences. U.S.A., 94, 14792-14797.

Tulving, E., \& Schacter, D. L. (1990). Priming and human memory systems. Science, 247, 301-306.

van Turennout, M., Bielamowicz, L., \& Martin, A. (2003). Modulation of neural activity during object naming: Effects of time and practice. Cerebral Cortex, 13, 381-391.

van Turennout, M., Ellmore, T., \& Martin, A. (2000). Long-lasting cortical plasticity in the object naming system. Nature Neuroscience, 3, 1329-1334.

Vuilleumier, P., Henson, R. N., Driver, J., \& Dolan, R. J. (2002). Multiple levels of object constancy revealed by event-related fMRI of repetition priming. Nature Neuroscience, 5, 491-499.

Wagner, A. D., Desmond, J. E., Demb, J. B., Glover, G. H., \& Gabrieli, J. D. E. (1997). Semantic repetition priming for verbal and pictorial knowledge: A functional MRI study of left inferior prefrontal cortex. Journal of Cognitive Neuroscience, 9, 714-726.

Wagner, A. D., Koutstaal, W., Maril, A., Schacter, D. L., \& Buckner, R. L. (2000). Task-specific repetition priming in left inferior prefrontal cortex. Cerebral Cortex, 10, 1176-1184.

Wagner, A. D., Pare-Blagoev, E. J., Clark, J., \& Poldrack, R. A. (2001). Recovering meaning: Left prefrontal cortex guides controlled semantic retrieval. Neuron, 31, 329-338.

Wheeler, M. E., Petersen, S. E., \& Buckner, R. L. (2000). Memory's echo: Vivid remembering reactivates sensory-specific cortex. Proceedings of the National Academv of Sciences, U.S.A., 97, 11125-11129.

Wiggs, C. L., \& Martin, A. (1998). Properties and mechanisms of perceptual priming. Current Opinion in Neurobiology. $8,227-233$. 


\section{This article has been cited by:}

1. A. W. Ellis, R. Ferreira, P. Cathles-Hagan, K. Holt, L. Jarvis, L. Barca. 2010. Word learning and the cerebral hemispheres: from serial to parallel processing of written words. Philosophical Transactions of the Royal Society B: Biological Sciences 364:1536, 3675-3696. [CrossRef]

2. E. A. Race, D. Badre, A. D. Wagner. 2009. Multiple Forms of Learning Yield Temporally Distinct Electrophysiological Repetition Effects. Cerebral Cortex . [CrossRef]

3. Joel L. Voss, Katherina K.Y. Hauner, Ken A. Paller. 2009. Establishing a relationship between activity reduction in human perirhinal cortex and priming. Hippocampus 19:9, 773-778. [CrossRef]

4. Elizabeth A. Race, Shanti Shanker, Anthony D. Wagner. 2009. Neural Priming in Human Frontal Cortex: Multiple Forms of Learning Reduce Demands on the Prefrontal Executive SystemNeural Priming in Human Frontal Cortex: Multiple Forms of Learning Reduce Demands on the Prefrontal Executive System. Journal of Cognitive Neuroscience 21:9, 1766-1781. [Abstract] [Full Text] [PDF] [PDF Plus]

5. Scott T. Grafton. 2009. Embodied Cognition and the Simulation of Action to Understand Others. Annals of the New York Academy of Sciences 1156:1, 97-117. [CrossRef]

6. E. Darcy Burgund, Yi Guo, Elyse L. Aurbach. 2009. Priming for letters and pseudoletters in mid-fusiform cortex: examining letter selectivity and case invariance. Experimental Brain Research 193:4, 591-601. [CrossRef]

7. Anja Soldan, Yunglin Gazes, H. John Hilton, Yaakov Stern. 2008. Aging Does Not Affect Brain Patterns of Repetition Effects Associated with Perceptual Priming of Novel ObjectsAging Does Not Affect Brain Patterns of Repetition Effects Associated with Perceptual Priming of Novel Objects. Journal of Cognitive Neuroscience 20:10, 1762-1776. [Abstract] [PDF] [PDF Plus]

8. Michael A. Yassa, Craig E.L. Stark. 2008. Multiple signals of recognition memory in the medial temporal lobe. Hippocampus 18:9, 945-954. [CrossRef]

9. A. S. Ghuman, M. Bar, I. G. Dobbins, D. M. Schnyer. 2008. The effects of priming on frontal-temporal communication. Proceedings of the National Academy of Sciences 105:24, 8405-8409. [CrossRef]

10. Barbara J. Knowlton, Karin Foerde. 2008. Neural Representations of Nondeclarative Memories. Current Directions in Psychological Science 17:2, 107-111. [CrossRef]

11. Ingo G. Meister, Dorothee Buelte, Roland Sparing, Babak Boroojerdi. 2007. A repetition suppression effect lasting several days within the semantic network. Experimental Brain Research 183:3, 371-376. [CrossRef]

12. Uri Hasson, Howard C. Nusbaum, Steven L. Small. 2006. Repetition Suppression for Spoken Sentences and the Effect of Task DemandsRepetition Suppression for Spoken Sentences and the Effect of Task Demands. Journal of Cognitive Neuroscience 18:12, 2013-2029. [Abstract] [PDF] [PDF Plus]

13. Eleni Orfanidou, William D. Marslen-Wilson, Matthew H. Davis. 2006. Neural Response Suppression Predicts Repetition Priming of Spoken Words and PseudowordsNeural Response Suppression Predicts Repetition Priming of Spoken Words and Pseudowords. Journal of Cognitive Neuroscience 18:8, 1237-1252. [Abstract] [PDF] [PDF Plus]

14. John Suckling, Matthew H. Davis, Cinly Ooi, Alle Meije Wink, Jalal Fadili, Raymond Salvador, David Welchew, Levent Şendur, Vochita Maxim, Edward T. Bullmore. 2006. Permutation testing of orthogonal factorial effects in a language-processing experiment using fMRI. Human Brain Mapping 27:5, 425-433. [CrossRef]

15. Michael W. L. Chee, Joshua O. S. Goh, Vinod Venkatraman, Jiat Chow Tan, Angela Gutchess, Brad Sutton, Andy Hebrank, Eric Leshikar, Denise Park. 2006. Age-related Changes in Object Processing and Contextual Binding Revealed Using fMR AdaptationAge-related Changes in Object Processing and Contextual Binding Revealed Using fMR Adaptation. Journal of Cognitive Neuroscience 18:4, 495-507. [Abstract] [PDF] [PDF Plus]

16. Alex Martin, Stephen J Gotts. 2005. Making the causal link: frontal cortex activity and repetition priming. Nature Neuroscience 8:9, 1134-1135. [CrossRef]

17. Gagan S Wig, Scott T Grafton, Kathryn E Demos, William M Kelley. 2005. Reductions in neural activity underlie behavioral components of repetition priming. Nature Neuroscience 8:9, 1228-1233. [CrossRef] 